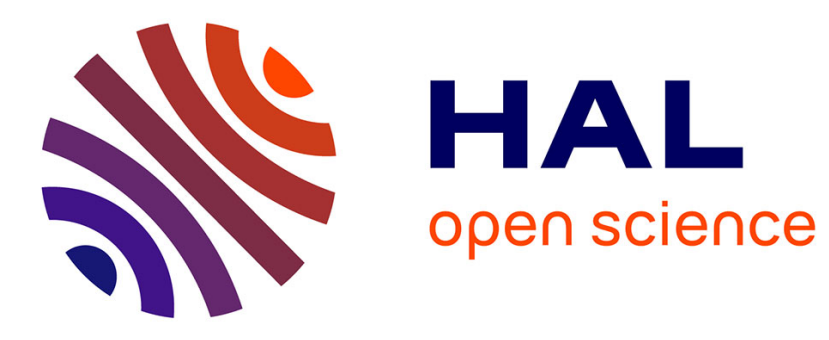

\title{
Photofragmentation spectroscopy of cold protonated aromatic amines in the gas phase
}

Géraldine Féraud, Michel Broquier, Claude Dedonder, Gilles Grégoire, Satchin Soorquia, Christophe Jouvet

\section{To cite this version:}

Géraldine Féraud, Michel Broquier, Claude Dedonder, Gilles Grégoire, Satchin Soorquia, et al.. Photofragmentation spectroscopy of cold protonated aromatic amines in the gas phase. Physical Chemistry Chemical Physics, 2014, 10.1039/C3CP54736A . hal-00920405

\section{HAL Id: hal-00920405 https://hal.science/hal-00920405}

Submitted on 28 Dec 2013

HAL is a multi-disciplinary open access archive for the deposit and dissemination of scientific research documents, whether they are published or not. The documents may come from teaching and research institutions in France or abroad, or from public or private research centers.
L'archive ouverte pluridisciplinaire $\mathbf{H A L}$, est destinée au dépôt et à la diffusion de documents scientifiques de niveau recherche, publiés ou non, émanant des établissements d'enseignement et de recherche français ou étrangers, des laboratoires publics ou privés. 


\section{Photofragmentation spectroscopy of cold protonated aromatic amines in the gas phase}

Géraldine Féraud $^{\mathrm{a}}$, Michel Broquier ${ }^{\mathrm{b}, \mathrm{c}}$, Claude Dedonder-Lardeux ${ }^{\mathrm{a}, \mathrm{c}}$, Gilles Grégoire ${ }^{\mathrm{d}}$, Satchin Soorkia ${ }^{\mathrm{b}}$ and Christophe Jouvet ${ }^{\mathrm{a}, \mathrm{c}}$

a PIIM, Aix-Marseille Université, CNRS UMR 7345, Avenue Escadrille Normandie-Niémen, 13397 Marseille Cedex 20, France

' Institut des Sciences Moléculaires d'Orsay, CNRS UMR 8214, Université Paris Sud 11, 91405 Orsay Cedex, France

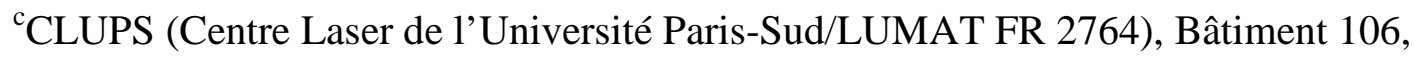
Université Paris Sud 11, 91405 Orsay Cedex, France

${ }^{\mathrm{d}}$ Laboratoire de Physique des Lasers, Université Paris 13, Sorbonne Paris Cité, CNRS UMR 7538, 93430 Villetaneuse, France

Corresponding Author: christophe.jouvet@univ-amu.fr 


\begin{abstract}
The electronic spectroscopy of cold protonated aromatic amines, aniline $\mathrm{H}^{+}$ $\mathrm{C}_{6} \mathrm{H}_{5}-\mathrm{NH}_{3}{ }^{+}$, benzylamine $\mathrm{H}^{+} \mathrm{C}_{6} \mathrm{H}_{5}-\mathrm{CH}_{2}-\mathrm{NH}_{3}{ }^{+}$and phenethylamine $\mathrm{H}^{+} \mathrm{C}_{6} \mathrm{H}_{5}-\left(\mathrm{CH}_{2}\right)_{2}-$ $\mathrm{NH}_{3}{ }^{+}$has been investigated experimentally in a large spectral domain and is compared to that of their hydroxy- homologues ( $\mathrm{OH}$ containing). In the low energy region, the electronic spectra are similar to their neutral analogues, which reveals that their first excited state is of $\pi \pi^{*}$ character. A second transition is observed from 0.5 to $1 \mathrm{eV}$ above the origin band, which is assigned to the excitation of the $\pi \sigma^{*}$ state. In these protonated amine molecules, there is a competition between different fragmentation channels, some of them being specific of the UV excitation and are not observed in low-energy collision induced dissociation experiment. Besides, a drastic change in the fragmentation branching ratio can be observed within a very short energy range that reveals the complex excited state dynamics and fragmentation processes in these species. The experimental observations can be rationalized with a simple qualitative model, the $\pi \pi * / \pi \sigma^{*}$ model(PCCP-2002), which predicts that the excited state dynamics is controlled by the crossing between the $\pi \pi^{*}$ excited state and a $\pi \sigma *$ state repulsive along the $\mathrm{XH}(\mathrm{X}$ being $\mathrm{O}$ or $\mathrm{N})$ coordinate.
\end{abstract}

Keywords: excited states dynamics, photofragmentation spectroscopy, cold ion trap, protonated amino acids 


\section{Introduction}

The photochemistry of protonated aromatic amino acids has been the subject of many studies $^{1-5}$ and is still not fully understood. The spectroscopic experiments have shown that the fragmentation is isomer dependent, which is not yet explained. ${ }^{1-3}$ Time-resolved and ion/neutral coincidence experiments have shown that the dynamics resulting from the photon absorption is quite complex and occurs on a very wide timescale extending from femtosecond to second. ${ }^{6-14}$ In amino acids, it has been postulated that the excited charge transfer states $\left(\pi \pi^{*} \mathrm{CO}\right.$ and $\pi \sigma^{*}{ }_{\mathrm{NH} 3}$ in which one electron is transferred from the aromatic ring toward the peptide chain), accessible upon absorption of one UV photon, play a central role in the fragmentation pathways. ${ }^{15,16}$ Upon this electron transfer, the amino acid part becomes hypervalent and thus quite unstable. Sub-picosecond excited state lifetimes have indeed been measured in tryptamine and tryptophan when excited at $4.67 \mathrm{eV} .{ }^{12,10,16,15,9}$ However, the exact nature of the states involved and the link between fragmentation pathways and spectroscopy has not been clearly evidenced yet experimentally, although predicted theoretically. In particular, the calculations have predicted a low-lying $\pi \sigma^{*}$ excited state repulsive along the $\mathrm{NH}$ coordinate, whereby an electron is promoted from the $\pi$-ring to the $\sigma^{*} \mathrm{NH}_{3}{ }^{+}$moiety. ${ }^{16,15}$ The dynamics of the $\pi \pi^{*}$ state is triggered by its crossing with the $\pi \sigma^{*}$ state, which further crosses with the ground state, as shown for $-\mathrm{OH}$ and $-\mathrm{NH}$ aromatic molecules (neutral phenol and substituted phenols, indole).

The ground state of protonated aniline has been already studied by infrared dissociation spectroscopy using the messenger technique. ${ }^{17}$ In this experiment, the two most stable isomers coexist, one with proton on the amino group $\left(\right.$ aniline $\left.\mathrm{H}^{+}\right)$and the other one with proton on the cycle (para and/or ortho positions), in agreement with calculations indicating that the ground state energies of these isomers are only separated by $8 \mathrm{~kJ} / \mathrm{mol} .{ }^{17}$ However, under solvation conditions like in an electrospray ionization source, protonation of aniline occurs preferentially on the amino group. ${ }^{1819202122232425262728293031}$ We will see that electronic spectroscopy is an approach to assign the protonation site.

We recorded the photofragmentation spectrum of a selection of protonated aromatic amine molecules (Fig. 1), from the smallest to the largest: aniline $\mathrm{H}^{+}\left(\mathrm{C}_{6} \mathrm{H}_{5}-\mathrm{NH}_{3}{ }^{+}, \mathrm{m} / \mathrm{z} 94\right)$, benzylamine ${ }^{+}\left(\mathrm{C}_{6} \mathrm{H}_{5}-\mathrm{CH}_{2}-\mathrm{NH}_{3}{ }^{+}, \mathrm{m} / \mathrm{z}\right.$ 108) and phenethylamine $\mathrm{H}^{+}(\mathrm{PEA})\left(\mathrm{C}_{6} \mathrm{H}_{5^{-}}\left(\mathrm{CH}_{2}\right)_{2^{-}}\right.$ 
$\mathrm{NH}_{3}{ }^{+}, \mathrm{m} / \mathrm{z}$ 122). We also studied their three hydroxy- substituted analogs, with the -OH group in para position on the phenyl chromophore: 4-aminophenolH ${ }^{+}\left(\mathrm{OH}-\mathrm{C}_{6} \mathrm{H}_{4}-\mathrm{NH}_{3}{ }^{+}, \mathrm{m} / \mathrm{z} 110\right)$, 4-hydroxybenzylamine $\mathrm{H}^{+} \quad\left(\mathrm{OH}-\mathrm{C}_{6} \mathrm{H}_{4}-\mathrm{CH}_{2}-\mathrm{NH}_{3}{ }^{+}, \quad \mathrm{m} / \mathrm{z} \quad 124\right)$ and tyramine $\mathrm{H}^{+}$ $\left(\mathrm{OH}-\mathrm{C}_{6} \mathrm{H}_{4}-\left(\mathrm{CH}_{2}\right)_{2}-\mathrm{NH}_{3}{ }^{+}, \mathrm{m} / \mathrm{z}\right.$ 138).

With this approach, we examine the influence of the alkyl chain length $\left(-\left(\mathrm{CH}_{2}\right)_{\mathrm{n}}-\mathrm{NH}_{3}{ }^{+}\right.$, with $\mathrm{n}=0,1$ and 2) in both phenyl and phenol chromophores on the spectroscopy and dynamics of protonated aromatic amines en route to the protonated amino acids, i.e., phenylalanine and tyrosine.<smiles>[NH3+]c1ccccc1</smiles>

anilineH $^{+}$<smiles>[NH3+]c1ccc(O)cc1</smiles>

4-aminophenolH ${ }^{+}$<smiles>[NH3+]Cc1ccccc1</smiles>

benzylamineH ${ }^{+}$ (1-phenylmethanamineH ${ }^{+}$)<smiles>[NH3+]Cc1ccc(O)cc1</smiles>

4-hydroxybenzylamineH ${ }^{+}$ (4-(aminomethyl)phenolH ${ }^{+}$)<smiles>[NH3+]CCc1ccccc1</smiles>

phenethylamine ${ }^{+}$ (2-phenylethanamine ${ }^{+}$)<smiles>[NH3+]CCc1ccc(O)cc1</smiles>

tyramine $\mathrm{H}^{+}$ (4-(2-aminoethyl)phenolH $\mathrm{H}^{+}$

Fig. 1 Scheme of the protonated molecules with the protonation site on the amino group as energetically most favorable in solution. The IUPAC name is indicated in parentheses.

In this paper, we present vibrationally resolved photo-fragmentation spectra of mass-selected protonated ions in a Paul trap cooled at cryogenic temperature in a large spectral range up to $\sim 8000 \mathrm{~cm}^{-1}(\sim 1 \mathrm{eV})$ above the band origin. The ions are sufficiently cooled in the ion trap such that low frequency vibrations due to the flexible side chain are resolved. It is shown that, in most cases, the fragmentation pathways change from the first electronic state to the second one, and even within the first excited state for the larger molecules. The overall behavior of 
the UV photodynamics in these systems can be understood with a simple model, the $\pi \pi * / \pi \sigma^{*}$ model, ${ }^{32}$ supported by ab initio calculations.

\section{Experiment}

The electronic spectra of the protonated aromatic amines were obtained via parent ion photofragment spectroscopy in a cryogenically-cooled quadrupole ion trap (Jordan TOF Products, Inc.). ${ }^{33}$ The setup is similar to the one developed by Wang and Wang. ${ }^{34}$ The protonated ions are produced in an electrospray ionization source built at Aarhus University. ${ }^{14}$ At the exit of the capillary, ions are trapped in an octopole trap for $90 \mathrm{~ms}$. They are extracted by applying a negative pulse of c.a. $50 \mathrm{~V}$ and are further accelerated to $120 \mathrm{~V}$ by a second pulsed voltage just after the exit electrode. This time sequence of pulsed voltages produces ion packets with duration between $500 \mathrm{~ns}$ and $1 \mu \mathrm{s}$. The ions are driven by a couple of electrostatic lenses toward the Paul trap biased at $120 \mathrm{~V}$ so that the ions enter the trap gently avoiding fragmentation induced by collision. A mass gate placed at the entrance of the trap allows selecting the parent ion. The Paul trap is mounted on the cold head of a cryostat (Coolpak Oerlikon) connected to a water-cooled He compressor. Helium as buffer gas is injected in the trap using a pulsed valve (General valve) triggered $1 \mathrm{~ms}$ before the ions enter the trap. The ions are trapped and thermalized at a temperature around $50 \mathrm{~K}$ through collisions with the buffer gas. The ions are kept in the trap for several tens of ms before the photodissociation laser is triggered. This delay is necessary to ensure thermalization of ions and efficient pumping of the He buffer gas from the trap to avoid collision induced dissociation of the ions during the extraction towards the $1.5 \mathrm{~m}$ long time-of-flight mass spectrometer. After laser excitation, the ions are stored in the trap for a delay that can be varied between 20 and $90 \mathrm{~ms}$ before extraction to the TOF mass spectrometer. Full mass spectrum is recorded on a micro channel plates (MCP) detector with a digitizing storage oscilloscope interfaced to a PC. The photofragmentation yield detected on each fragment is normalized to the parent ion signal and the laser power.

The photo-dissociation laser is an OPO laser from EKSPLA, which has a $10 \mathrm{~Hz}$ repetition rate, a resolution of $8 \mathrm{~cm}^{-1}$ and a scanning step of $0.1 \mathrm{~nm}$. The laser is mildly focused in the trap with a $1 \mathrm{~m}$ focal lens and the laser power is around $20 \mathrm{~mW}$ in the UV. Part of the UV spectra have been recorded at the CLUPS facility in Orsay on a similar setup, but using a $\mathrm{Nd}$ :YAG pumped dye laser with a higher spectral resolution $\left(0.2 \mathrm{~cm}^{-1}\right)$. 


\section{Calculations}

$A b$ initio calculations have been performed with the TURBOMOLE program package, ${ }^{35}$ making use of the resolution-of-the-identity (RI) approximation for the evaluation of the electron-repulsion integrals. ${ }^{36}$ The equilibrium geometry of the protonated species in their ground states $\left(\mathrm{S}_{0}\right)$ have been determined at the MP2 (Møller-Plesset second order perturbation theory) level. Excitation energies and equilibrium geometry of the lowest excited singlet state $\left(\mathrm{S}_{1}\right)$ have been determined at the RI-CC2 level. Calculations were performed with the augmented correlation-consistent polarized valence double-zeta (aug-cc-pVDZ) basis set[REF] except for aniline $\mathrm{H}^{+}$for which the augmented correlation-consistent polarized valence triple-zeta (aug-cc-pVTZ) basis sets $^{37}$ was used. The vibrations in the ground and excited states have been calculated and the electronic spectra simulated using the Pgopher software $^{38}$ for Frank Condon analysis.

\section{Results}

The electronic spectra of all the molecules investigated in the present study are shown in Erreur! Source du renvoi introuvable. for aniline $\mathrm{H}^{+}$and 4 -aminophenolH ${ }^{+}$, in Fig. 3 for benzylamine $\mathrm{H}^{+}$and 4-hydroxybenzylamine $\mathrm{H}^{+}$and in Fig. 4 for phenethylamine $\mathrm{H}^{+}$and tyramine $\mathrm{H}^{+}$. For each molecule, we reported the photofragmentation yield on each fragment channel as a function of the laser wavelength. For all the molecules, $\mathrm{NH}_{3}$ loss (black line) is the most intense fragmentation channel. Other fragmentation channels are detected depending on the molecules: $\mathrm{H}$ atom loss (red line) and $\mathrm{C}_{\alpha}-\mathrm{C}_{\beta}$ bond cleavage (blue line). 


\subsection{Electronic spectroscopy}

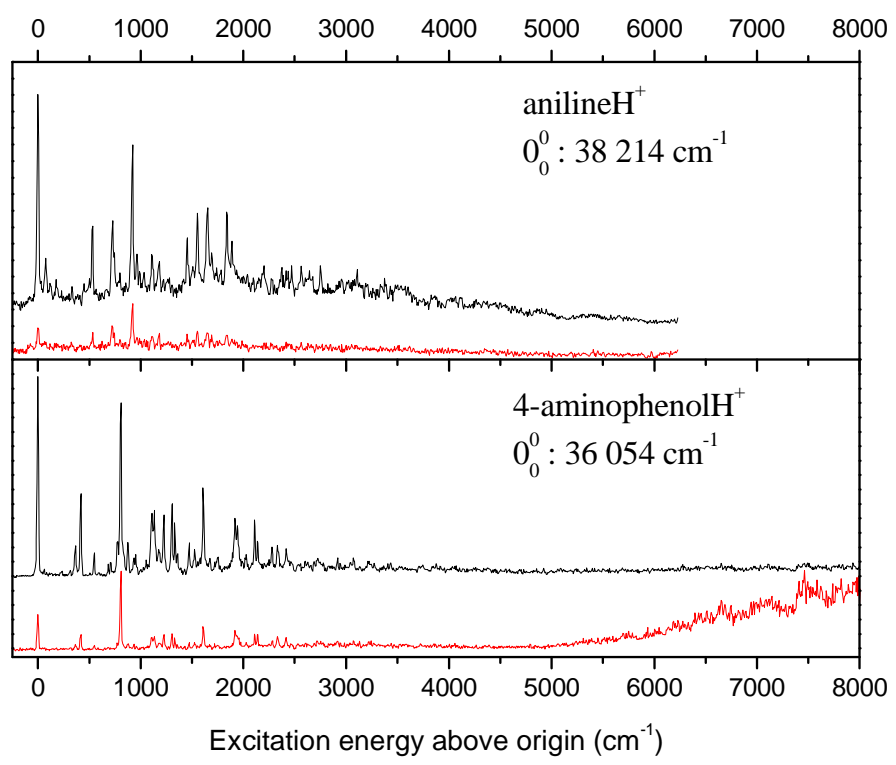

Fig. 2 Comparison of aniline $\mathrm{H}^{+}$(upper) and 4-aminophenolH ${ }^{+}$(lower) photodissociation spectra. The origin is the $0-0$ transition of the first excited state. The fragmentation channels are the $\mathrm{NH}_{3}$-loss (black) and H-loss (red).

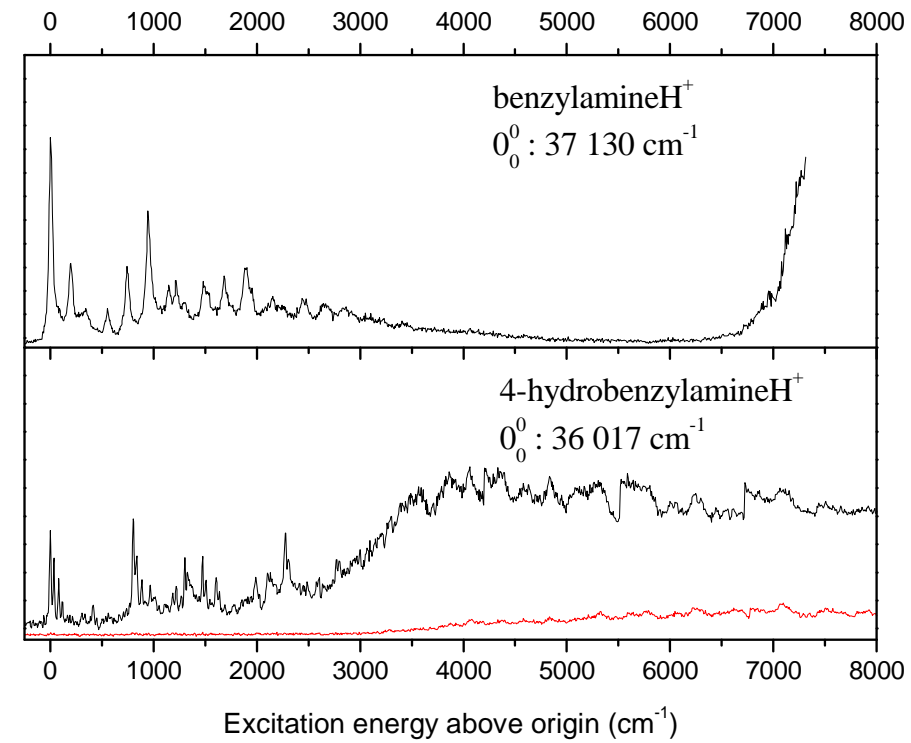

Fig. 3 Comparison of protonated benzylamine and 4-hydroxybenzylamine photodissociation spectra. The origin is the 0-0 transition of the first excited state. The fragmentation channels 
are $\mathrm{NH}_{3}$-loss (black) and $\mathrm{H}$-loss (red) for protonated 4-hydroxybenzylamine. Only $\mathrm{NH}_{3}$-loss is observed for protonated benzylamine.

As a general finding (Fig. 2, 3 and 4), the protonated molecules have a electronic spectrum similar to their neutral analogues corresponding to $\pi \pi^{*}$ transition (see Fig. SI1 in Supporting Information), i.e. an intense $0_{0}{ }^{0}$ transition observed in the $35000-38000 \mathrm{~cm}^{-1}$ region together with a few active modes $\left(v_{1}, v_{12}\right.$ around $800 / 900 \mathrm{~cm}^{-1}$ and $v_{6}$ around $\left.500 \mathrm{~cm}^{-1}\right)$. No bands have been observed further to the red of these absorption features. Higher in energy, a second unstructured band appears around $40000 \mathrm{~cm}^{-1}$. As will be shown in the following, this transition can be interpreted as the excitation of a $\pi \sigma^{*}$ state where the electron is transferred from the $\pi$ orbital on the aromatic ring to the $\sigma *$ orbital of the ammonium group. For the higher energy region, we are limited by the wavelength range of the tunable laser. This experimental limitation precludes the observation of the second band in aniline $\mathrm{H}^{+}$, which should be higher in energy (vide infra).

The origin of the aniline $\mathrm{H}^{+}$transition is at $38215 \mathrm{~cm}^{-1}$, which is highly blue-shifted with respect to neutral aniline $\left(34030 \mathrm{~cm}^{-1}\right){ }^{39}$ A similar blue shift of the $0_{0}{ }^{0}$ transition is observed for 4-aminophenolH $\mathrm{H}^{+}$(the first transition is at $31395 \mathrm{~cm}^{-1}$ in the neutral molecule ${ }^{40}$ and $36020 \mathrm{~cm}^{-1}$ in the protonated species) while for the other amines, benzylamine, hydroxybenzylamine, phenethylamine and tyramine, the transitions of the protonated species are very close to those of their neutral parent. This effect is linked to the deconjugation of the nitrogen lone pair with the addition of a proton on the amino group in aniline and 4-aminophenol.

For all these molecules, the width of the vibronic transitions is on the order of $7 \mathrm{~cm}^{-1}$, except for benzylamineH $\mathrm{H}^{+}$, which exhibits broader bands (FWHM $\sim 45 \mathrm{~cm}^{-1}$ ). The profile of the band origin recorded at higher resolution is presented in the Supporting Information (Fig. SI2): no spectral feature or low frequency progression is observed so that the spectral broadening can be assigned to a very short lifetime of the excited state of benzylamineH ${ }^{+}$. The FWHM being around $45 \mathrm{~cm}^{-1}$, the excited state lifetime is in the order of $100 \mathrm{fs}$. The FWHM of anilineH ${ }^{+}$ 
measured at high resolution was $\sim 7 \mathrm{~cm}^{-1}$, which includes the rotational contour, so that the excited state lifetime is greater than 1 ps.

Shown in Erreur! Source du renvoi introuvable. are the spectra for protonated phenethylamine (PEA) and tyramine. For these two molecules, at variance with the smaller amines, the $0_{0}{ }^{\circ}$ transition is weak and presents a low frequency progression of bands separated by $45 \pm 5 \mathrm{~cm}^{-}$ ${ }^{1}$. Since the low frequency progression has a bell shape structure, the position of the $0_{0}{ }^{0}$ transition for the two molecules cannot be determined precisely. Although the bands present an overlapping low frequency progression, the general aspect of the spectrum of protonated PEA looks similar to the spectrum of neutral PEA. The first member of the progression clearly observed is at $37577 \mathrm{~cm}^{-1}$, which is not very different from the $0_{0}{ }^{0}$ transitions of the different conformers of neutral phenethylamine (ranging from 37538 to $37629 \mathrm{~cm}^{-1}$ ). ${ }^{4142}$

According to Sun \& Bernstein, ${ }^{42}$ the band at $\sim 673 \mathrm{~cm}^{-1}$ is assigned to the $6 \mathrm{~b}$ mode and the intense band at $\sim 1500 \mathrm{~cm}^{-1}$ above the band origin can be assigned to the $6 \mathrm{~b}_{0}{ }^{1} 12_{0}{ }^{1}$ combination band. In protonated tyramine (Fig. 4), the spectrum is dominated by long low frequency vibrational progressions, which are superimposed on other vibrational modes. This results in broad bands, the first two being separated by c.a. $800 \mathrm{~cm}^{-1}$ and the $v_{6}$ mode seems to be absent (or weak), as in protonated benzylamine. 


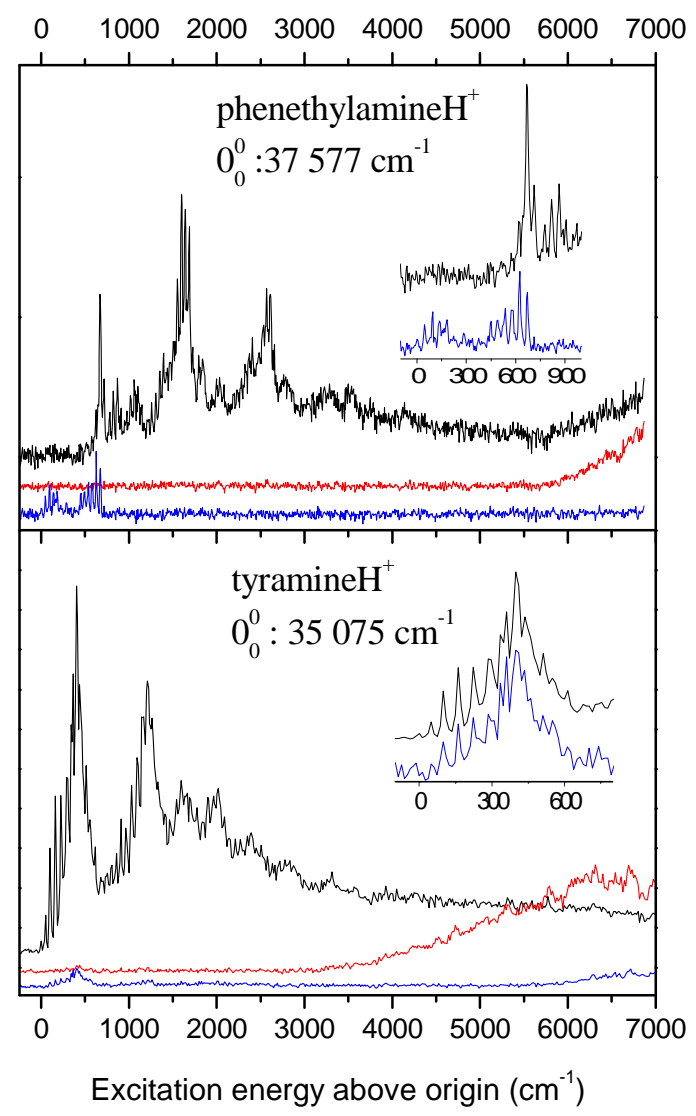

Fig. 4 Comparison of tyramine $\mathrm{H}^{+}$(lower spectrum) and phenethylamine $\mathrm{H}^{+}$(upper one) photodissociation spectra. The origin is the 0-0 transition of the first excited state. For these molecules there are 3 major fragments: $\mathrm{H}$-loss is in red, $\mathrm{NH}_{3}$ loss in black and $\mathrm{C}_{\alpha}-\mathrm{C}_{\beta}$ bond breaking in blue.

\subsection{Fragmentation channels}

As it can be seen in Fig. 2, 3 and 4, several fragmentation channels are observed in these protonated molecules and compete with each others. Depending on the molecules, their branching ratios can depend on the excess energy in $\pi \pi^{*}$ state and change from the first to second electronic states. In particular, excitation of the second electronic state leads to an increase of the H-loss channel.

Near the $0_{0}{ }^{0}$ transition, the most intense fragmentation channel is $\mathrm{NH}_{3}$-loss: for benzylamine $\mathrm{H}^{+}$and 4-hydroxybenzylamine $\mathrm{H}^{+}$, this is the only fragmentation channel observed, for aniline $\mathrm{H}^{+}$and 4 -aminophenolH $\mathrm{H}^{+}$, the $\mathrm{H}$-loss channel is also detected, for PEA and tyramine $\mathrm{H}^{+}$, which possess the longest alkyl chain $\left(\left(\mathrm{CH}_{2}\right)_{2}-\mathrm{NH}_{3}{ }^{+}\right), \mathrm{C}_{\alpha}-\mathrm{C}_{\beta}$ bond cleavage 
is observed. It should be noted that, for all these protonated molecules, $\mathrm{NH}_{3}$ loss is the most abundant channel in collision induced dissociation (CID). ${ }^{43}$ The other fragments are not detected under CID at low energy (below $5 \mathrm{eV}$ ) except for aniline $\mathrm{H}^{+}$for which $\mathrm{H}$-loss is observed, ${ }^{29}$ and thus seem to be specific of UV photoexcitation.

For PEA and tyramine $\mathrm{H}^{+}$, there is a huge contrast in the photofragmentation as compared to the smaller amines. At low energy, the $\mathrm{C}_{\alpha}-\mathrm{C}_{\beta}$ bond cleavage constitutes a new fragmentation path so that the global fragmentation pattern is more complex and the branching ratio between the different fragmentation channels evolves drastically within a short energy range. The $\mathrm{C}_{\alpha^{-}}$ $\mathrm{C}_{\beta}$ bond cleavage leads to $\mathrm{m} / \mathrm{z} 92$ and m/z 91 fragments: they are obtained by a proton transfer from $\mathrm{NH}_{3}{ }^{+}$to the cycle and $\mathrm{C}_{\alpha}-\mathrm{C}_{\beta}$ bond cleavage (giving $\mathrm{m} / \mathrm{z}$ 92) and by a successive $\mathrm{H}$ transfer (giving m/z 91).

For PEA, at $673 \mathrm{~cm}^{-1}$ above the band origin, the fragmentation channel shifts from the $\mathrm{C}_{\alpha}-\mathrm{C}_{\beta}$ bond cleavage to the $\mathrm{NH}_{3}$-loss channel (leading to $\mathrm{m} / \mathrm{z} 105$ fragment). As seen in the inset of Erreur ! Source du renvoi introuvable., both fragmentation channels coexist over a small energy range of $\sim 100 \mathrm{~cm}^{-1}$ preceding the shift, and the $\mathrm{NH}_{3}$-loss channel rapidly gains intensity: of very low intensity (if present) on the band at $578 \mathrm{~cm}^{-1}$, of equal intensity as the $\mathrm{C}_{\alpha}-\mathrm{C}_{\beta}$ bond cleavage channel on the $631 \mathrm{~cm}^{-1}$ band and largely dominant on the $673 \mathrm{~cm}^{-1}$ band. Beyond this energy, the $\mathrm{C}_{\alpha}-\mathrm{C}_{\beta}$ bond breaking channel disappears. This behavior in the two fragmentation channels demonstrates that the $\mathrm{NH}_{3}$-loss channel opens at around $650 \mathrm{~cm}^{-1}$ of excess energy in the excited state, with an increasing yield. The bell-shape Franck Condon structure of the $0_{0}{ }^{0}$ transition is still present on the second band for the $\mathrm{C}_{\alpha}-\mathrm{C}_{\beta}$ bond cleavage channel, but on the $\mathrm{NH}_{3}$-loss channel, the intensity of the band at $673 \mathrm{~cm}^{-1}$ band is much greater, which indicates that the fragmentation yield is lower in the $C_{\alpha}-C_{\beta}$ bond rupture channel than in the $\mathrm{NH}_{3}$-loss channel, i.e., the fragmentation yield is not unity. The abrupt change (within $\sim 100 \mathrm{~cm}^{-1}$ ) of the fragmentation pathway clearly means that the dynamics is changing in the excited state with excitation energy: such a sharp transition is unlikely to occur after internal conversion to the ground state because the total energy change between the two channels is $\sim 0.3 \%\left(100 \mathrm{~cm}^{-1} / 36000 \mathrm{~cm}^{-1}\right)$.

For tyramine $\mathrm{H}^{+}$, the fragmentation pattern is different than in PEA: all photofragmentation channels except $\mathrm{H}$-loss coexist at low energy. The $\mathrm{C}_{\alpha}-\mathrm{C}_{\beta}$ bond rupture channel, leading to $\mathrm{m} / \mathrm{z} 108$, is very weak and is only present up to $\sim 500 \mathrm{~cm}^{-1}$ above origin, as in PEA. 
In contrast to PEA, the main fragmentation channel at low energy is $\mathrm{NH}_{3}$-loss $(\mathrm{m} / \mathrm{z} 121$ photofragment). On the other hand, the H-loss channel, which is absent in the low-energy region, is the most abundant fragment in the high-energy region. $\mathrm{NH}_{3}$-loss at low energy and $\mathrm{H}$-loss at higher energy is similar to the fragmentation pattern in 4-aminophenol $\mathrm{H}^{+}$.

\subsection{Electronic state calculations}

Table 1 Summary of the calculations for the first two excited states of protonated aromatic amines. calculations have been performed with the CC2 method and the aug-cc-pVDZ basis sets for all molecules, except aniline $\mathrm{H}^{+}$for which the aug-cc-pVTZ basis set was used. All energies are in $\mathrm{eV}$.

\begin{tabular}{|c|c|c|c|c|c|c|}
\hline Protonated Molecules & $\begin{array}{l}S_{1}-S_{0} \\
\text { Vert. }^{\text {(a) }}\end{array}$ & $\begin{array}{c}\mathrm{S}_{1}-\mathrm{S}_{0}\left(\pi \pi^{*}\right) \\
\text { Adia }^{(b)}\end{array}$ & $\begin{array}{c}\mathrm{S}_{2}-\mathrm{S}_{0}\left(\pi \sigma^{*}\right) \\
\text { Vert. }^{(\mathrm{c})}\end{array}$ & $\begin{array}{c}\delta \mathrm{ZPE} \\
\mathrm{S}_{1}-\mathrm{S}_{0}{ }^{(\mathrm{d})}\end{array}$ & Calc. $0_{0}{ }^{0(\mathrm{e})}$ & Exp. $0_{0}{ }^{0(\mathrm{f})}$ \\
\hline aniline $^{+}$ & 5.28 & 5.09 & 6.46 & -0.19 & 4.90 & 4.74 \\
\hline 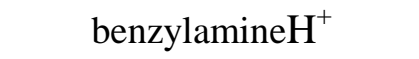 & 5.02 & 4.85 & 5.85 & -0.20 & 4.65 & 4.60 \\
\hline phenethylamine $\mathrm{H}^{+}$ & 5.09 & 4.90 & 5.86 & -0.16 & 4.70 & 4.66 \\
\hline 4-aminophenolH ${ }^{+}$ & 4.81 & 4.62 & 5.38 & -0.19 & 4.42 & 4.47 \\
\hline 4-hydroxybenzylamine $\mathrm{H}^{+}$ & 4.94 & 4.76 & 5.50 & -0.20 & 4.56 & 4.47 \\
\hline tyramine $\mathrm{H}^{+}$ & 4.70 & 4.59 & 5.10 & -0.19 & 4.39 & 4.35 \\
\hline
\end{tabular}

${ }^{a} S_{1} \leftarrow S_{0}$ vertical transition energy ; ${ }^{b} S_{1} \leftarrow S_{0}$ adiabatic transition energy ; ${ }^{c} S_{2} \leftarrow S_{0}$ vertical transition energy ; difference in zero-point energy between the ground and first excited states $\left(\delta Z P E S_{0}-S_{1}\right)$, the $\delta Z P E$ values in italic have not been calculated but are an average of those calculated for the other molecules, all around $0.2 \mathrm{eV} ;{ }^{e}$ calculated $S_{1} \leftarrow S_{0}$ origin transition ; ${ }_{\text {experimental }} S_{1} \leftarrow S_{0}$ origin transition .

For all molecules, protonation of the amino group leads to the most stable isomer in the ground electronic state (at the MP2 level of theory). Their excited state properties calculated at the CC2 level are reported in Table 1. In these molecules, the first excited state corresponds to a $\pi \pi^{*}$ transition. The second excited state has a charge transfer character, in which the active electron is transferred from the $\pi$ orbital to a Rydberg orbital centered on the protonated amino group. For planar or nearly planar molecules as aniline $\mathrm{H}^{+}$and 4-aminophenolH ${ }^{+}$, this corresponds to the $\pi \sigma^{*}$ state. For non planar systems, this Rydberg 
state on the amino group will still be called $\pi \sigma^{*}$ for sake of simplicity and by analogy with previous studies on protonated aromatic amino acids. ${ }^{15,16}$

Geometry optimizations of the ground and the first excited states have been done for all molecules (see Supplementary Information). For the small molecules, we found that the geometry changes between ground and excited states are relatively small. In PEA and tyramine $\mathrm{H}^{+}$(like in tyrosine), ${ }^{16}$ the proton pointing to the aromatic ring is much closer to the $\mathrm{C}_{2}$ carbon in the excited state than in the ground state, which induces a change in the planarity of the aromatic ring, the $\mathrm{H}$ atom linked to $\mathrm{C}_{2}$ being $10^{\circ}$ below the benzene plane. In addition, there is a torsion motion of the chain, which leads to low frequency active modes in the electronic spectrum.

There is a good agreement between the experimental and calculated $0_{0}{ }^{0}$ transitions of the first excited state when the variation in zero point energy ( $\delta \mathrm{ZPE}$ ) between the $\mathrm{S}_{0}$ and $\mathrm{S}_{1}$ states is taken into account. This $\delta \mathrm{ZPE}$ is within the same values $(0.16$ to $0.20 \mathrm{eV})$ for the four molecules (aniline $\mathrm{H}^{+}$, benzylamine $\mathrm{H}^{+}, \mathrm{PEA}$ and 4-hydroxybenzylamine $\mathrm{H}^{+}$) for which it has been calculated. For the other species, a $\delta \mathrm{ZPE}$ of $0.19 \mathrm{eV}$ has been estimated as the average of the previous ones. The adiabatic energy for the $\pi \pi^{*}$ transition in the protonated species with a hydroxyl group in para position, i.e., 4-aminophenolH $\mathrm{H}^{+}$, 4-hydroxybenzylamine $\mathrm{H}^{+}$and tyramine $\mathrm{H}^{+}$is located in the $4.4-4.6 \mathrm{eV}$ energy range.

Shown in Fig. are the vibrational simulations for the simplest molecules, i.e., aniline $\mathrm{H}^{+}$and protonated benzylamine. There is a good agreement between the experimental and simulated spectra that can therefore be assigned without ambiguity. In the case of aniline $\mathrm{H}^{+}$, the transition involving the $v_{6}$ mode at $530 \mathrm{~cm}^{-1}$ above the origin is not reproduced and its intensity in the experimental spectrum may be induced by a vibronic coupling with a higher electronic state. The good agreement between experiment and calculations indicate that indeed the proton is located on the amino group.

Moreover the vertical energy of the first excited state for the isomer with proton on the aromatic ring (in para position) has been calculated at $5.1 \mathrm{eV}$ (CC2lcc-pVDZ) but it undergoes a fast internal conversion through ring deformation ${ }^{44}$, which should lead to broad, unstructured absorption. If the proton is in ortho position, the calculated transition is around $3.8 \mathrm{eV}$, much lower than the observed transition. ${ }^{44}$ 
For protonated benzylamine the $S_{0}$ and $S_{1}$ geometries are quite similar and the spectral simulation performed does not exhibit low frequency progressions or sequences. Thus the observed broadening of the vibrational bands is most probably due to a fast non-radiative process, confirming what was deduced from higher spectral resolution experiment (section 4.1).
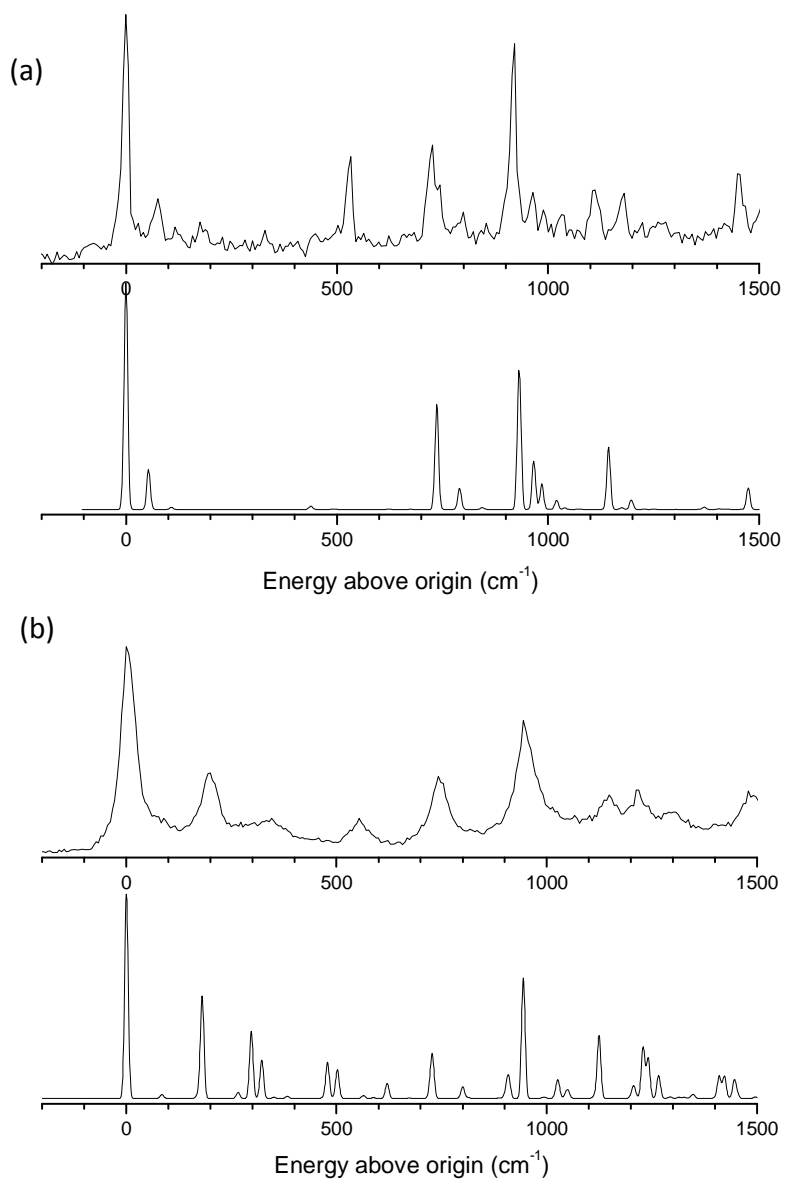

Fig. 5 Calculated spectra (lower panels) compared with the experimental ones (higher panels) for anilineH $\mathrm{H}^{+}$(a) and benzylamine $\mathrm{H}^{+}$(b). At this scale one clearly sees that the bands of benzylamine $\mathrm{H}^{+}$are broadened. 


\section{Discussion}

The comparison between the experimental electronic spectra recorded over a large spectral range and the calculations of the first excited states emphasizes the role of the $\pi \sigma^{*}$ state in the photodissociation of these protonated amine molecules. The $\pi \sigma^{*}$ state is calculated between 0.4 and $1 \mathrm{eV}$ above the origin of the $\pi \pi^{*}$ state. Indeed, the onset of the second band at high energy closely matches the calculated vertical gap between $\pi \pi^{*}$ and $\pi \sigma^{*}$ states (see Table 2), consistent with a direct excitation of this state at high energy. For aniline $\mathrm{H}^{+}$, the calculations indicate that the $\pi \sigma^{*}$ state has a vertical transition energy of $6.8 \mathrm{eV}$, so that it cannot be observed under our experimental conditions. For the other molecules, the slow onset of the high energy transition is either due to the repulsive nature of this potential, which is in agreement with the absence of any vibrational structure, or to a very fast non-radiative decay.

The $\pi \sigma^{*}$ state is characterized by an electron transfer from a $\pi$ orbital located on the ring to a $\sigma^{*}$ Rydberg type orbital localized on the $\mathrm{NH}_{3}{ }^{+}$ammonium group, the $\mathrm{C}^{-} \mathrm{NH}_{3}{ }^{+}$group becomes hypervalent and $\mathrm{NH}$ bonds become unstable as in $\mathrm{NH}_{4}{ }^{45-47}$ In protonated tryptamine $^{12}$ and tryptophan, ${ }^{9,117,16,11,15,13}$ this leads to the observation of the specific UV photofragmentation channels as $\mathrm{H}$-loss. Besides, $\mathrm{C}_{\alpha}-\mathrm{C}_{\beta}$ bond rupture is also detected in these later molecules for which the protonated amino group points towards the aromatic ring. In the protonated amines studied here, even near the origin transition of the $\pi \pi^{*}$ state, UV specific $\mathrm{H}$-loss or $\mathrm{C}_{\alpha}-\mathrm{C}_{\beta}$ bond cleavage channels are observed along with the $\mathrm{NH}_{3}$-loss, which is commonly observed in low-energy CID experiments. In the following, we will present a model to rationalize the competition between the different fragmentation channels in line with the more general $\pi \pi^{*} / \pi \sigma^{*}$ model $^{32}$ which has been shown to be quite successful in explaining the excited state dynamics of many neutral aromatic molecules containing hydroxyl $(\mathrm{OH})$ or azine $(\mathrm{NH})$ groups.

Table 2 Dissociation energies $(\Delta \mathrm{E})$ for the $\mathrm{H}$ loss channel and $\pi \pi^{*} / \pi \sigma^{*}$ energy gaps. $\Delta \mathrm{E}$ are calculated using the formula (1) and the $\pi \pi^{*} / \pi \sigma^{*}$ energy gap is deduced from the vertical energies of the $\pi \pi^{*}$ and $\pi \sigma^{*}$ states. All energies in $\mathrm{eV}$.

\begin{tabular}{|c|c|c|c|c|}
\hline \multirow[b]{2}{*}{ Molecules } & \multirow[b]{2}{*}{$\operatorname{Exp} 0_{0}^{0}$} & \multirow[b]{2}{*}{ Calc. $\Delta \mathrm{E}$} & Exp & Calc. \\
\hline & & & $S_{1}-S_{2}$ energy gap ${ }^{b}$ & $\pi \pi * / \pi \sigma^{*}$ energy gap \\
\hline aniline $^{+}$ & 4.74 & 3.26 & & 1.18 \\
\hline
\end{tabular}




\begin{tabular}{|c|c|c|c|c|}
\hline benzylamine $\mathrm{H}^{+}$ & 4.60 & 4.36 & 0.8 & 0.82 \\
\hline phenethylamine $\mathrm{H}^{+}$ & 4.66 & 4.60 & 0.7 & 0.77 \\
\hline 4-aminophenolH ${ }^{+}$ & 4.47 & 3.16 & 0.65 & 0.57 \\
\hline 4-hydroxybenzylamine $\mathrm{H}^{+}$ & 4.47 & $4.60^{\mathrm{a}}$ & 0.4 & 0.56 \\
\hline tyramine $\mathrm{H}^{+}$ & 4.35 & $4.82^{\mathrm{a}}$ & 0.37 & 0.40 \\
\hline
\end{tabular}

${ }^{a}$ these values are calculated at the MP2/aug-cc-pVDZ level of theory. ${ }^{b}$ measured on the H-loss channel except for benzylamine ${ }^{+}$.

Let us highlight the main findings, which support our simple qualitative model for the protonated species:

a) The electronic spectra of the protonated and neutral species are very similar (see Fig. SI1). The nature of the aromatic ring is weakly perturbed and the first electronic transition is essentially a $\pi \pi^{*}$ transition at low energy (below $4.8 \mathrm{eV}$ ). From $0.4 \mathrm{eV}$ to $1 \mathrm{eV}$ higher in energy, the second electronic $\pi \sigma^{*}$ state is reached.

b) For the simplest nearly planar protonated aromatic amines, i.e., aniline $\mathrm{H}^{+}$and 4-aminophenolH $\mathrm{H}^{+}$, the $\mathrm{H}$-loss channel is observed on the $0_{0}{ }^{0}$ transition of the $\pi \pi^{*}$ state. This strongly suggests an efficient coupling between the locally excited $\pi \pi^{*}$ state with the dissociative $\pi \sigma^{*}$ state. We can assign this H-loss channel to the NH bond rupture.

c) In benzylamine $\mathrm{H}^{+}$, the broad vibrational transitions indicate that the excited state lifetime is short (in the order of $\sim 100 \mathrm{fs}$ ). This shows that fast non-radiative decays are involved following the $\pi \pi^{*}$ excitation

d) For PEA, the fragmentation channels change abruptly within $\sim 100 \mathrm{~cm}^{-1}$.

The proposed scheme emphasizes the role of the $\mathrm{H}$ atom dynamics and has already been discussed in previous studies on aromatic amino acid fragmentations ${ }^{32,16}$ (see Fig. ).

The $\pi \pi^{*}$ excited state dynamics and further fragmentations are controlled by the presence of a quasi-dissociative $\pi \sigma^{*}$ state along the $\mathrm{NH}$ coordinate of the ammonium group (Fig. 6). The excited state lifetime is controlled by the energy of the first $\pi \pi^{*} / \pi \sigma^{*}$ crossing and the coupling between these two states. The evolution of the system is further controlled by a second crossing between the $\pi \sigma^{*}$ state and the $\pi \pi$ ground state, the ground state 
correlating with the $\mathrm{M}+\mathrm{H}^{+}$limit and the $\pi \sigma^{*}$ with the $\mathrm{M}^{+}+\mathrm{H}$ limit. The three $\mathrm{NH}$ bonds of the ammonium group are free in the case of aniline $\mathrm{H}^{+}$or 4 -aminophenolH $\mathrm{H}^{+}$, the $\mathrm{H}$-loss channel may occur from any of these bonds. In phenethylamine $\mathrm{H}^{+}$and tyramine $\mathrm{H}^{+}$, which possess the longest alkyl chain, the excited state geometry is such that one hydrogen atom of the ammonium group is pointing towards the aromatic ring, leading to a proton transfer to the $\pi$-ring as in the protonated aromatic amino acids.

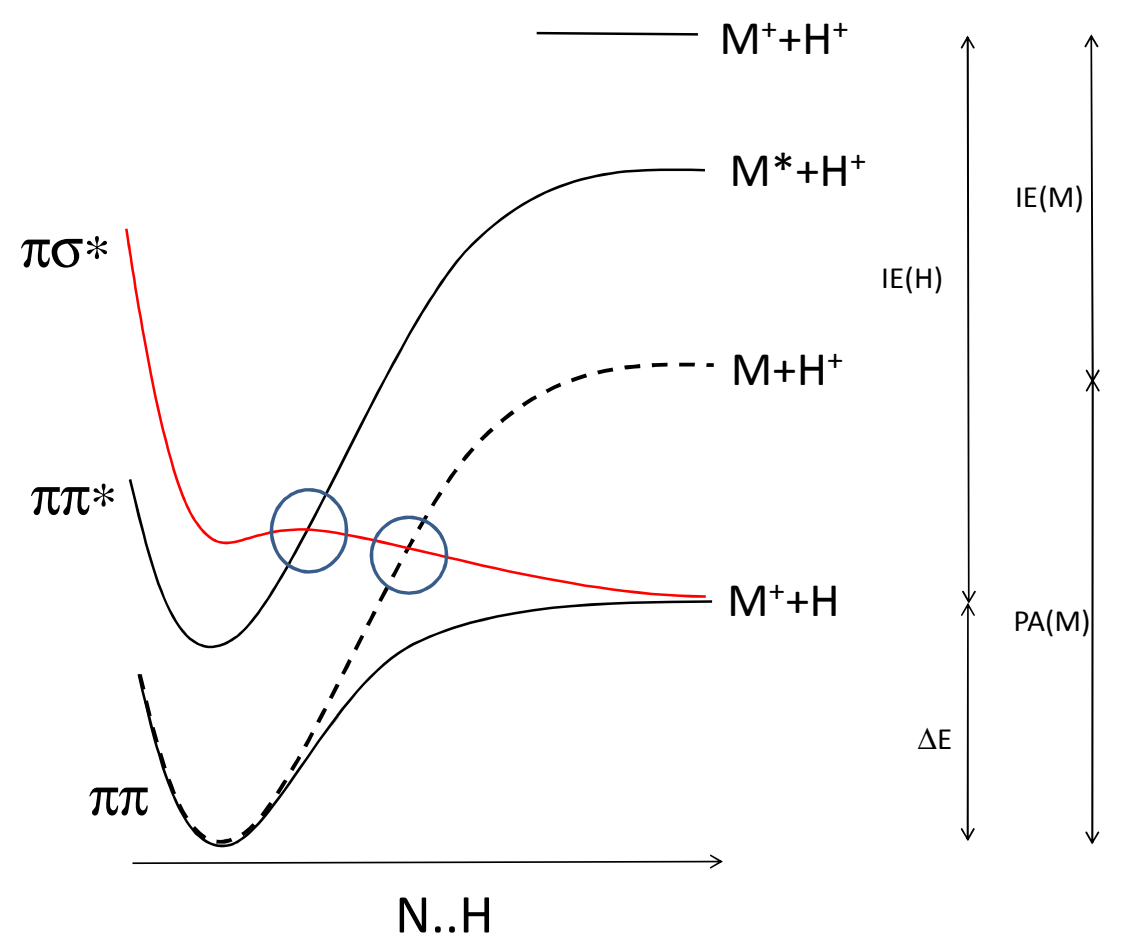

Fig. 6: Scheme of the proposed mechanism. The fragmentation is triggered by the repulsive nature of the $\pi \sigma^{*}$ state localized on the amino group and depends on the coupling with the $\pi \pi^{*}$ state, the energy of the $\pi \sigma^{*} / \pi \pi^{*}$ crossing (width of the barrier from $\pi \pi^{*}$ to $\pi \sigma^{*}$ ) and the energy of the second $\pi \sigma^{*} / \pi \pi$ crossing.

Let us see how the experimental findings can be interpreted with this model.

(a) At the $0_{0}{ }^{0}$ transition, H-loss is observed in some species but not all of them. The dissociation limit $(\Delta \mathrm{E})$ in $\mathrm{M}^{+}+\mathrm{H}$ can be calculated from the formula:

$$
\Delta \mathrm{E}=\mathrm{IE}(\mathrm{M})+\mathrm{PA}(\mathrm{M})-\mathrm{IE}(\mathrm{H}),
$$


where $\operatorname{IE}(\mathrm{M})$ and $\mathrm{IE}(\mathrm{H})$ are the ionization energies of the molecule and hydrogen and $\mathrm{PA}(\mathrm{M})$ is the proton affinity of the molecule. $\operatorname{IE}(\mathrm{M}), \mathrm{PA}(\mathrm{M})$ and $\mathrm{IE}(\mathrm{H})$ are known values from the literature.[NIST] The values of the dissociation energies $\Delta \mathrm{E}$ as well as the $\pi \pi^{*} / \pi \sigma^{*}$ energy gaps are reported in Table 2. It can be clearly seen that for two protonated species, aniline $\mathrm{H}^{+}$ and 4-aminophenolH $\mathrm{H}^{+}$, the $\mathrm{M}^{+}+\mathrm{H}$ dissociation limit is much lower $(<0.7 \mathrm{eV})$ than for the other ones and well below the excitation energy. Thus in these protonated species, the barrier from $\pi \pi^{*}$ to $\pi \sigma^{*}$ is low enough to be tunneled through, and the energetically accessible $\mathrm{H}$ loss channel is observed. The calculated $\pi \pi^{*} / \pi \sigma^{*}$ energy gap is relatively high for 4-aminophenolH $\mathrm{H}^{+}(0.5 \mathrm{eV})$ and even larger for aniline $\mathrm{H}^{+}(1.18 \mathrm{eV})$. Nevertheless, the low $\mathrm{H}$ dissociation energy limit implies that the slope of the repulsive $\pi \sigma^{*}$ curve is steep, which lowers the energy of the $\pi \pi * / \pi \sigma^{*}$ conical intersection sufficiently so that the $\mathrm{H}$-loss is indeed observed even at the band origin. It is worth mentioning that the yield of the H-loss versus $\mathrm{NH}_{3}$ loss is greater in 4-aminophenolH+ than in aniline $\mathrm{H}^{+}$, which is support by the smaller $\pi \pi^{*} / \pi \sigma^{*}$ energy gap in the former. For the other ions, this channel is nearly energetically closed such that the exit channel goes through the crossing with the $\pi \pi$ ground state (hindered H-loss), which leads to internal conversion and CID-like fragmentation (statistical fragmentation).

(b) The second point is that the lifetime of first electronic states varies on at least one order of magnitude ( $\sim 100 \mathrm{fs}$ for benzylamine $\mathrm{H}^{+}$and larger than $1 \mathrm{ps}$ for the other molecules). In benzylamine $\mathrm{H}^{+}$, due to the geometry of the molecular ion and the nature of the orbitals, there is a large overlap between the $\pi^{*}$ orbital and the $\sigma^{*}$ orbital (see Fig. ). This overlap should result in a strong coupling between the $\pi \pi^{*}$ and $\pi \sigma^{*}$ state, which then should lead to a very short lifetimeHere, the deformation is much more important than in catechol where the lifetime has been measured at $10 \mathrm{ps}$ (ref stavros) and thus the very short lifetime is not surprising. One would have expected the $\pi^{*} / \sigma^{*}$ overlap in 4-hydroxybenzylamine $\mathrm{H}^{+}$and phenethylamine $\mathrm{H}^{+}$to be quite similar or even better than in benzylamine $\mathrm{H}^{+}$since one proton of the $\mathrm{NH}_{3}$ group is pointing toward the aromatic ring. However, no fast relaxation is observed experimentally. The calculations indicate that the $\sigma^{*}$ orbital has no overlap with the $\pi^{*}$-orbital (see Fig. ), therefore the coupling should be smaller and the lifetime is expected to be longer. 
$\pi *$ orbital

Cs symmetry
benzylamineH

benzylamineH $^{+}$

Cs symmetry broken

4-hydroxybenzylamineH+

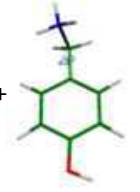

phenylethylamineH ${ }^{+}$

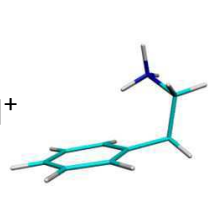

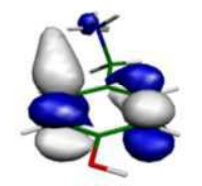

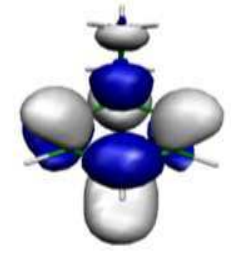

$\sigma *$ orbital
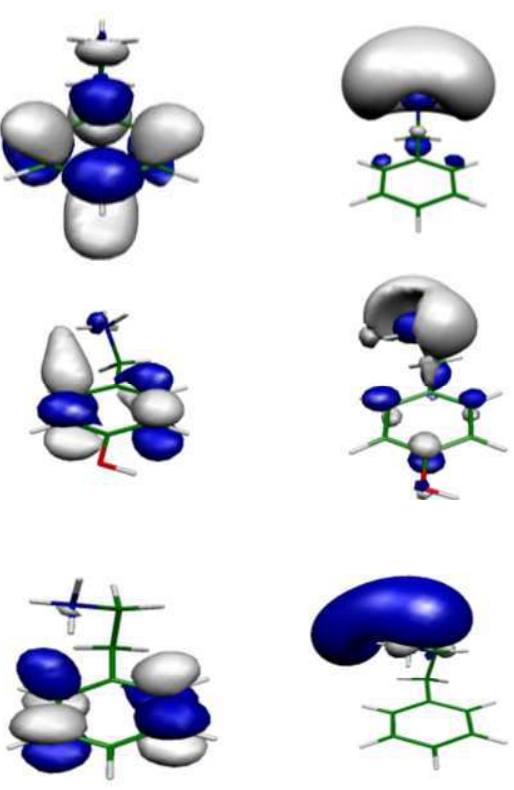

Fig. $7 \pi^{*}$ and $\sigma^{*}$ orbitals of benzylamineH $\mathrm{H}^{+}$(upper), 4-hydroxybenzylamine $\mathrm{H}^{+}$(middle) and phenethylamineH ${ }^{+}$(lower). In benzylamine $\mathrm{H}^{+}$, the overlap between these orbitals is large and a strong $\pi \pi * / \pi \sigma^{*}$ coupling is expected. In 4-hydroxybenzylamine $\mathrm{H}^{+}$and phenethylamine $\mathrm{H}^{+}$the overlap is small and the electronic coupling should be small.

(c) In protonated PEA and tyramine, fragments corresponding to the $\mathrm{C}_{\alpha}-\mathrm{C}_{\beta}$ bond rupture $\left(\mathrm{m} / \mathrm{z} 91\right.$ and 92 photo-fragments of PEA and m/z 108 photo-fragment of tyramine $\mathrm{H}^{+}$) are observed at low energy and this channel closes abruptly at c.a. $690 \mathrm{~cm}^{-1}$ above the band origin. The $\mathrm{C}_{\alpha}-\mathrm{C}_{\beta}$ bond rupture is a minor fragmentation channel for both molecules, being the only one at low energy in PEA, whereas in tyramine $\mathrm{H}^{+}$it is in competition with the $\mathrm{NH}_{3}$-loss. The $\mathrm{C}_{\alpha}-\mathrm{C}_{\beta}$ bond rupture is commonly found in the $\mathrm{UV}$ photodissociation spectra of protonated aminoacids: ${ }^{6}$ it has been calculated for both protonated tyrosine and protonated tryptophan ${ }^{16}$ and in the latter case it has been detected through the m/z 132 photo-fragment (with an additional $\mathrm{H}$ transfer). ${ }^{78}$ For protonated phenethylamine, the first excited state of the isomer with the proton on the aromatic cycle has been calculated $1.1 \pm 0.1 \mathrm{eV}$ lower in energy than the $\pi \pi^{*}$ adiabatic energy for the structure with proton on the amino group.

In protonated phenethylamine, the fragmentation yield is weak at the origin and increases with energy: the intensity of the band at $673 \mathrm{~cm}^{-1}$ above the origin is higher for the opening channel $\left(\mathrm{NH}_{3}\right.$-loss), so that the fragmentation yield increases. This means that the fragmentation yield for the $\mathrm{C}_{\alpha}-\mathrm{C}_{\beta}$ bond cleavage channel may be quite low and therefore may be in competition with other channels such as intersystem crossing or fluorescence. Since the 
proton transfer to the $\pi$-ring in the $S_{1}$ state requires some deformation of the aromatic ring, it could be a slow process (ns timescale, similar to the radiative process), and the higher energy channel ( $\mathrm{NH}_{3}$-loss) should be faster. By analogy with the other protonated amines, we assign the new channel to the hindered $\mathrm{H}$-loss along the $\mathrm{NH}$ coordinate, resulting in internal conversion through $\pi \sigma^{*} / \pi \pi$ conical intersection. The $\pi \pi^{*} / \pi \sigma^{*}$ energy gap is smaller in tyramine $\mathrm{H}^{+}$than in phenethylamine $\mathrm{H}^{+}$, therefore the conical intersection is lower in energy and the $\mathrm{NH}_{3}$ loss channel is open at the band origin.

The observed dynamical behavior of the protonated ions can be explained within the frame of this simple model. However, it is clear that it is only qualitative and more theoretical works are required to make it quantitative. Moreover, we have only discussed one non-radiative mechanism -fragmentation via $\pi \pi * / \pi \sigma^{*}$ dynamics- but other mechanisms such as intersystem crossing or internal conversion through pyramidalization as in benzene can play an important role. ${ }^{48}$ Finally, for the amines with a phenol chromophore, it is not clear whether the H-loss channel corresponds only to the repulsive $\pi \sigma^{*}$ state on $\mathrm{NH}$ or to the one on $\mathrm{OH}$ as evidenced in neutral phenol ${ }^{324950}$ or to both. But the calculations locate the $\pi \sigma^{*}$ state on the $\mathrm{OH}$ group higher in energy than the $\pi \sigma^{*}$ state localized on the ammonium group. Nevertheless, the most salient features of the experimental observations can still be explained. The model predicts that strong variations in the excited state lifetimes should be observed when the energy is scanned over the electronic absorptions.

\section{Conclusions}

We have presented in this paper the electronic spectra of the simplest protonated aromatic amine molecules. The vibrational analysis shows that the electronic structure of the aromatic ring is weakly perturbed by protonation on the amino group. Upon excitation, the fragmentation pattern is quite rich with several fragmentation channels in competition. Nevertheless, the complex fragmentation behavior can be rationalized using a simple model, the $\pi \pi^{*} / \pi \sigma^{*}$ model developed in the last ten years, which can be applied to closed-shell $-\mathrm{OH}$ and $-\mathrm{NH}$ containing aromatic molecules both neutral and protonated. For protonated phenethylamine and tyramine, the very drastic change of the fragmentation branching ratio within $650 \mathrm{~cm}^{-1}$ represents a challenge for theoretical calculations. 


\section{Acknowledgements}

This work has been supported by the Aix-Marseille Université and Université Paris-Sud 11, by the ANR research Grant (ANR2010BLANC040501), the RTRA “triangle de la physique” COMOVA. We acknowledge the use of the computing facility clusters GMPCS of the LUMAT federation (FR LUMAT 2764) and MAGI of the University Paris 13. Stéphane Coussan and Gaël Roussin are thanked for their help in setting up the experiment in Marseille.

Thanks are due to the chemists of Institut des Sciences Moléculaires de Marseille for their help. 


\section{References}

1. J. A. Stearns, S. Mercier, C. Seaiby, M. Guidi, O. V. Boyarkin, and T. R. Rizzo, J. Am. Chem. Soc., 2007, 129, 11814-11820.

2. T. N. Wassermann, O. V. Boyarkin, B. Paizs, and T. R. Rizzo, J. Am. Soc. Mass Spectrom., 2012, 23, 1029-1045.

3. T. R. Rizzo, J. A. Stearns, and O. V Boyarkin, Int. Rev. Phys. Chem., 2009, 28, 481515.

4. D. Nolting, C. Marian, and R. Weinkauf, Phys. Chem. Chem. Phys., 2004, 6, $2633-$ 2640 .

5. F. O. Talbot, T. Tabarin, R. Antoine, M. Broyer, and P. Dugourd, J. Chem. Phys., 2005, 122, 074310.

6. B. Lucas, M. Barat, J. A. Fayeton, M. Perot, C. Jouvet, G. Grégoire, and S. Brøndsted Nielsen, J. Chem. Phys., 2008, 128, 164302.

7. V. Lepere, B. Lucas, M. Barat, J. A. Fayeton, Y. J. Picard, C. Jouvet, P. C $\square \operatorname{arc} \square$ abal, I. B. Nielsen, C. Dedonder-Lardeux, G. Grégoire, and M. Fujii, Phys. Chem. Chem. Phys., 2007, 9, 5330-5334.

8. V. Lepere, B. Lucas, M. Barat, J. A. Fayeton, Y. J. Picard, C. Jouvet, P. C $\square$ arc $\square$ abal, I. B. Nielsen, C. Dedonder-Lardeux, G. Grégoire, and M. Fujii, J. Chem. Phys., 2007, 127, 134313.

9. H. Kang, C. Jouvet, C. Dedonder-Lardeux, S. Martrenchard, G. Grégoire, C. Desfrançois, J.-P. Schermann, M. Barat, and J. A. Fayeton, Phys. Chem. Chem. Phys., 2005, 7, 394-398.

10. H. Kang, C. Dedonder-Lardeux, C. Jouvet, G. Grégoire, C. Desfrançois, J.-P. Schermann, M. Barat, and J. A. Fayeton, J. Phys. Chem. A, 2005, 109, 2417-2420.

11. H. Kang, C. Dedonder-Lardeux, C. Jouvet, S. Martrenchard, G. Grégoire, C. Desfrançois, J.-P. Schermann, M. Barat, and J. A. Fayeton, Phys. Chem. Chem. Phys., 2004, 6, 2628-2632.

12. H. Kang, C. Jouvet, C. Dedonder-Lardeux, S. Martrenchard, C. Charriere, G. Gregoire, C. Desfrancois, J. P. Schermann, M. Barat, and J. A. Fayeton, J. Chem. Phys., 2005, 122, 084307.

13. G. Grégoire, B. Lucas, M. Barat, J. A. Fayeton, C. Dedonder-Lardeux, and C. Jouvet, Eur. Phys. J. D, 2009, 51, 109-116. 
14. J. U. Andersen, H. Cederquist, J. S. Forster, B. A. Huber, P. Hvelplund, J. Jensen, B. Liu, B. Manil, L. Maunoury, S. B. Nielsen, U. V. Pedersen, J. Rangama, H. T.

Schmidt, S. Tomita, and H. Zettergren, Phys. Chem. Chem. Phys., 2004, 6, 2676-2681.

15. G. Grégoire, C. Jouvet, C. Dedonder, and A. L. Sobolewski, Chem. Phys., 2006, 324, 398-404.

16. G. Grégoire, C. Jouvet, C. Dedonder, and A. L. Sobolewski, J. Am. Chem. Soc., 2007, 129, 6223-6231.

17. F. M. Pasker, N. Solcà, and O. Dopfer, J. Phys. Chem. A, 2006, 110, 12793-12804.

18. F. A. Carey and R. J. Sundberg, Advanced Organic Chemistry, Plenum Pre., 1995.

19. M. B. Smith and J. March, Advanced Organic Chemistry: Reactions, Mechanisms, and Structure, 5th ed., Wiley: New., 2001.

20. R. Stewart, The Proton: Applications to Organic Chemistry, Academic P., 1985.

21. G. A. Olah, K. Dunne, D. P. Kelly, and Y. K. Mo, J. Am. Chem. Soc., 1972, 94, 74387447.

22. R. Flammang, N. Dechamps, L. Pascal, Y. Haverbeke, P. Gerbaux, P.-C. Nam, and M. Nguyen, Lett. Org. Chem., 2004, 1, 23-30.

23. Y. K. Lau, K. Nishizawa, A. Tse, R. S. Brown, and P. Kebarle, J. Am. Chem. Soc., 1981, 103, 6291-6295.

24. S. K. Pollack, J. L. Devlin, K. D. Summerhays, R. W. Taft, and W. J. Hehre, J. Am. Chem. Soc., 1977, 99, 4583-4584.

25. Y. K. Lau and P. Kebarle, J. Am. Chem. Soc., 1976, 98, 7452-7453.

26. K. V. Wood, D. J. Burinsky, D. Cameron, and R. G. Cooks, J. Org. Chem., 1983, 48, 5236-5242.

27. R. L. Smith, L. J. Chyall, B. J. Beasley, and H. I. Kenttamaa, J. Am. Chem. Soc., 1995, 117, 7971-7973.

28. A. G. Harrison and Y. P. Tu, Int. J. Mass Spectrom., 2000, 196, 33-43.

29. Y. A. Ranasinghe and G. L. Glish, J. Am. Soc. Mass Spectrom., 1996, 7, 473-481.

30. A. Bagno and F. Terrier, J. Phys. Chem. A, 2001, 105, 6537-6542.

31. S.-W. Lee, H. Cox, W. A. Goddard, and J. L. Beauchamp, J. Am. Chem. Soc., 2000, 122, 9201-9205.

32. A. L. Sobolewski, W. Domcke, C. Dedonder-Lardeux, and C. Jouvet, Phys. Chem. Chem. Phys., 2002, 4, 1093-1100. 
33. I. Alata, J. Bert, M. Broquier, C. Dedonder, G. Feraud, G. Grégoire, S. Soorkia, E. Marceca, and C. Jouvet, J. Phys. Chem. A, 2013, 117, 4420-4427.

34. X.-B. Wang and L.-S. Wang, Rev. Sci. Instrum., 2008, 79, 073108.

35. R. Ahlrichs, M. Bär, M. Häser, H. Horn, and C. Kölmel, Chem. Phys. Lett., 1989, 162, $165-169$.

36. C. Hattig, J. Chem. Phys., 2003, 118, 7751-7761.

37. D. E. Woon and T. H. Dunning, J. Chem. Phys., 1993, 98, 1358-1371.

38. C. M. Western, PGOPHER, a Program for Simulating Rotational Structure, C. M. Western, University of Bristol, http://pgopher.chm.bris.ac.uk, ; available at http:// pgopher.chm.bris.ac.uk.

39. J. C. D. Brand, D. R. Williams, and T. J. Cook, J. Mol. Spectrosc., 1966, 20, 359-380.

40. S. Wategaonkar and S. Doraiswamy, J. Chem. Phys., 1996, 105, 1786.

41. S. J. Martinez, J. oseph C. Alfano, and D. H. Levy, J. Mol. Spectrosc., 1993, 158, 8292.

42. S. Sun and E. R. Bernstein, J. Am. Chem. Soc., 1996, 118, 5086-5095.

43. http://www.massbank.eu/MassBank/.

44. I. Alata, Ph.D. thesis, Université Paris-Sud 11, 2012.

45. S. Nonose, T. Taguchi, K. Mizuma, and K. Fuke, Eur. Phys. J. D, 1999, 9, 309-311.

46. K. Fuke, R. Takasu, and F. Misaizu, Chem. Phys. Lett., 1994, 229, 597-603.

47. S. Nonose, T. Taguchi, F. Chen, S. Iwata, and K. Fuke, J. Chem. Phys., 2002, 106, 5242-5248.

48. W. Radloff, V. Stert, T. Freudenberg, I. V Hertel, C. Jouvet, C. Dedonder-Lardeux, and D. Solgadi, Chem. Phys. Lett., 1997, 281, 20-26.

49. M. N. R. Ashfold, G. A. King, D. Murdock, M. G. D. Nix, T. A. A. Oliver, and A. G. Sage, Phys. Chem. Chem. Phys., 2010, 12, 1218-1238.

50. G. A. Pino, A. N. Oldani, E. Marceca, M. Fujii, S. Ishiuchi, M. Miyazaki, M. Broquier, C. Dedonder, and C. Jouvet, J. Chem. Phys., 2010, 133, 124313. 